\title{
Pemanfaatan Limbah Serbuk Kayu Didesa Ranjok Kecamatan Gunung Sari Kabupaten Lombok Barat Menjadi Biomass Pellet Sebagai Sumber Energi Terbarukan
}

\author{
Lalu Fathur Maulana*, Hervan Imami Ghozali, Moh. Haykal Fikri, \\ Eka Indriani Agustina, Muhamad Ali \\ Universitas Mataram, Kota Mataram, Indonesia
}

\begin{abstract}
Kata Kunci: $\quad$ Abstrak: Energi alternatif merupakan pilihan untuk mengatasi krisis energi saat energi alternatif, ini, salah satu energi alternatif yang bisa dimanfaatkan adalah biomassa yang pemanfaatan sangat berpotensi untuk dikembangkan menjadi energi terbarukan. Kayu serbuk kayu, merupakan salah satu sumber energi yang diharapkan yang dapat menggantikan biopelet sumber bahan bakar minyak. Bahan bakar dari kayu yang umum digunakan secara langsung adalah serbuk gergaji/penyomilan. Penelitian ini bertujuan untuk mengolah serbuk limbah kayu menjadi bahan bakar biopellet.Penelitian dilaksanakan pada tanggal 15 Juli- 31Agustus 2019 di . Bahan utama adalah serbuk kayu dan tapioka sebagai perekat. Serbuk kayu yang telah diolah berupa serat/fiber.
\end{abstract}

\section{Korespondensi: faturlalu21@gmail.com}

\section{PENDAHULUAN}

Kelangkaan bahan bakar yang berakibat pada semakin tingginya harga minyak bumi di pasar dunia mendorong pencarian sumber-sumber energi alternatif yang terbarukan. Kayu merupakan salah satu sumber energi yang diharapkan dapat menggantikan sumber bahan bakar minyak, namun apabila kayu dijadikan sebagai bahan bakar secara langsung mempunyai sifat-sifat yang kurang menguntungkan, antara lain kadar air yang tinggi, mengeluarkan banyak asap dan abu. Bahan bakar dari kayu yang umum digunakan secara langsung adalah serbuk gergaji/penyomilan. Serbuk kayu melalui proses lanjutan berupa pencacahan, pengeringan, penepungan dan pengepresan yang dapat dijadikan bahan bakar dinamakan pelet kayu. Jenis bahan bakar ini merupakan bahan bakar kayu alternatif yang dipandang memiliki keunggulan. Penggunaan pelet kayu sebagai bahan bakar dapat dilakukan dengan menggunakan tungku untuk pemanas ruangan atau tungku memasak. Pelet kayu menjadi perhatian utama saat ini karena faktor kemudahan dalam bahan baku dan memiliki karakteristik yang ramah lingkungan. Serbuk kayu ini dapat diperoleh dari beragam sumber limbah perkayuan. Jumlah serbuk kayu yang dihasilkan dari eksploitasi/pemanenan dan pengolahan kayu bulat sangat banyak.

Serbuk kayu merupakan limbah industri penggergajian kayu. Serbuk kayu dari hasil pemotongan selama ini hanya dibiarkan begitu saja dan banyak menimbulkan masalah. Limbah serbuk kayu yang di biarkan membusuk, ditumpuk atau dibakar yang kesemuanya berdampak negatif terhadap lingkungan sehingga penanggulanganannya perlu dipertimbangkan lagi. Salah satu jalan yang dapat di tempuh yaitu dengan memanfaatkannya menjadi produk yang bernilai tambah dengan bantuan teknologi aplikatif, sehingga hasilnya mudah di sosialisasikan kepada masyrakat. Serta merubah pola pikir masyarakat yang statis 
akan pemanfaatan limbah serbuk kayu, sekaligus mengurangi dampak negatif dari limbah tersebut.

Kekurangan dari serbuk kayu sebagai bahan bakar adalah memiliki nilai kalori yang rendah, densitas (massa jenis) energi yang rendah. Sedangkan kelebihan dari serbuk kayu sebagai bahan bakar adalah dapat menghasilkan panas pembakaran yang tinggi, lebih murah bila dibandingkan dengan minyak tanah atau rang kayu dan masa bakar jauh lebih lama dari pada arang biasa.

Tujuan Penelitian

1. Mengurangi pencemaran lingkungan limbah serbuk kayu melalui pemanfaatan pengolahan menjadi bahan bakar Biopellet.

2. Meningkatkan kesadaran, pemahaman serta inovasi kepada masyarakat terkait pemanfaatan limbah serbuk kayu.

Rumusan Masalah

1. Apa dan bagaimana proses produksi limbah kayu menjadi Biopellet?

2. Bagaimana antusiasme masyarakat terkait pemanfaatan limbah serbuk gergaji sebagai Biopellet?

\section{METODE KEGIATAN}

\section{Lokasi Penelitian}

Penelitian dilaksanakan di desa Ranjok kec. Gunung Sari kab. Lombok Barat, dengan pertimbangan proses produksi bertempat di KPH Rinjani Barat Pelangan Tastura pabrik Pelet Kayu, desa Bentek kab. Lombok Utara.

\section{Pengumpulan Data}

Data dikumpulkan dengan metode wawancara, survey pendataan/pencatatan dan pengamatan langsung, di lapangan dengan obyek penelitian : industri pertukangan, pabrik pelet kayu dan berbagai pihak terkait.

\begin{tabular}{|c|c|c|c|}
\hline No & Metode & Sumber Data & Jenis Data \\
\hline 1 & $\begin{array}{l}\text { Pencatatan/Pendataan } \\
\text { jumlah pengrajin kayu } \\
\text { dan limbah kayu }\end{array}$ & $\begin{array}{l}\text { Industri pertukangan, } \\
\text { penyomilan kayu meliputi } \\
\text { pengrajin dan tukang kayu di } \\
\text { desa Ranjok }\end{array}$ & $\begin{array}{l}\text { Jenis kayu yang sering digunakan } \\
\text { Bentuk pemanfaatan } \\
\text { Jumlah serbuk kayu yang di } \\
\text { hasilkan per-minggu dalam satuan } \\
\text { karung } \\
\text { Harga limbah jika dijual }\end{array}$ \\
\hline 2 & Wawancara & $\begin{array}{l}\text { Kepala Desa Ranjok, Sekrertaris } \\
\text { Desa Ranjok, dan Kadus masing } \\
\text { dusun di desa Ranjok. }\end{array}$ & $\begin{array}{l}\text { Persepsi tentang pemanfaatan } \\
\text { limbah kayu } \\
\text { Penggunaan limbah kayu di } \\
\text { masyarakat } \\
\text { Persepsi tentang keberadaan } \\
\text { industri } \\
\text { pelet kayu }\end{array}$ \\
\hline 3 & Pengamatan lapangan & $\begin{array}{l}\text { Industri pertukangan, pabrik } \\
\text { Biomass Pellet Kayu. }\end{array}$ & $\begin{array}{l}\text { Jenis limbah industri pertukangan } \\
\text { Proses pembuatan pelet kayu }\end{array}$ \\
\hline
\end{tabular}




\section{Kerangka Analisis}

Analisis penggunaan limbah serbuk kayu dalam masyarakat, serta peran para pihak dalam pemanfaatannya di masyarakat dan dalam industri pengolahan kayu, dilakukan melalui alur pikir seperti : Gambar 1

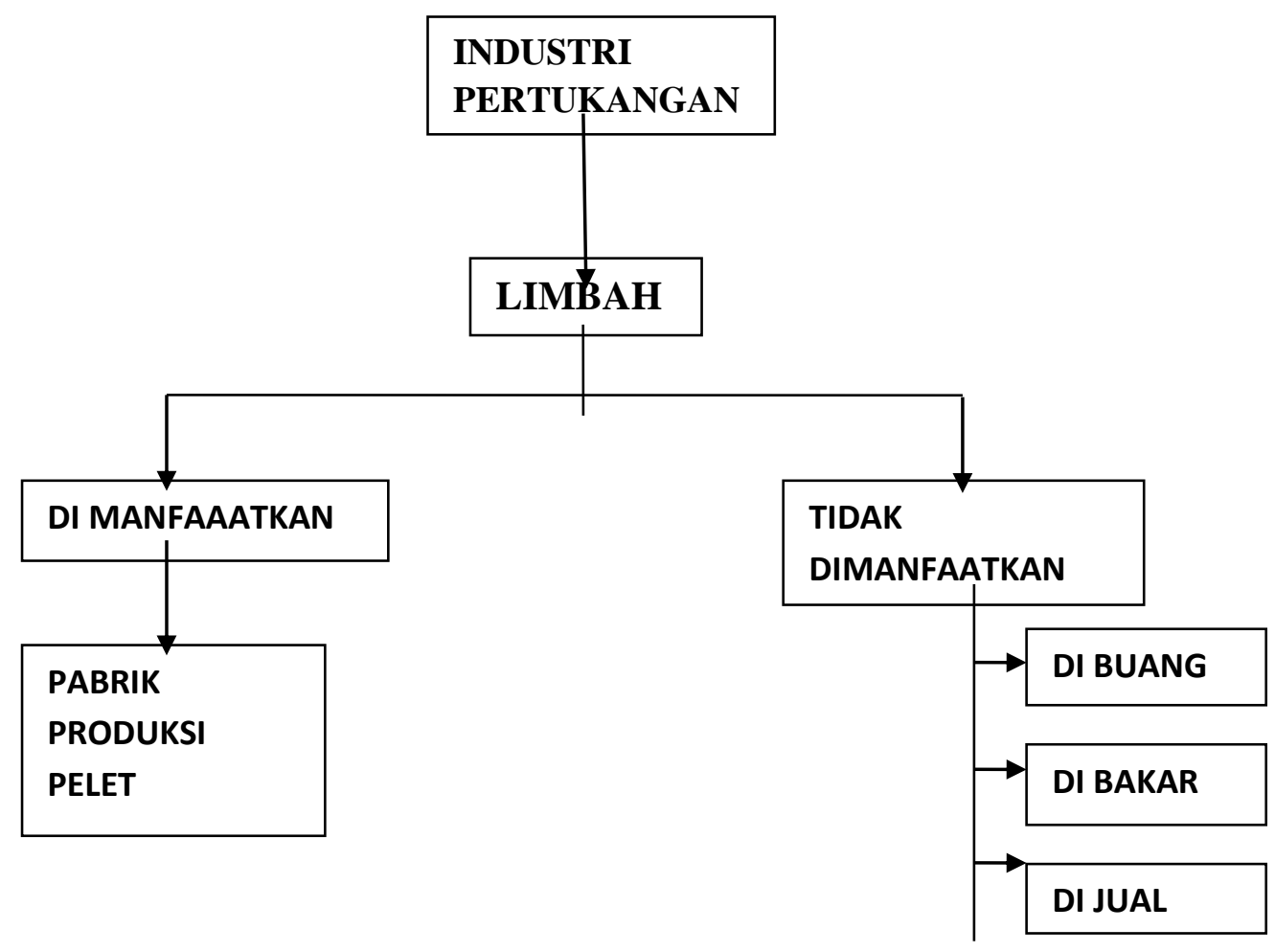

Terlihat bahwa pemanfaatan serbuk kayu sebagai bahan bakar biomass pelet dalam rangka mengurangi limbah serbuk kayu di lingkungan masyarakat, perlu diketahui besarnya potensi pemanfaatannya sehingga limbah kayu tidak di buang atau di bakar lagi, namun proses pengolahannya perlu sosialisasikan agar pemanfaatannya di pergunakan secara maksimal. Limbah yang berasal dari industri pertukangan sangat berpontesi untuk dimanfaatkan menjadi biomassa bahan bakar pelet.

\section{Analisis Data}

Data yang terkumpul diolah dan dianalisis melalui tabulasi data untuk selanjutnya dibahas secara deskriptif, yaitu (1) Untuk mengetahui jumlah pengrajin kayu dengan mengidentifikasi lokasi pengindustrian (2) Untuk mengetahui potensi kebutuhan dan pemanfaatan serbuk kayu di desa Ranjok yaitu dengan mengidentifikasi jumlah industri pengolahan kayu yang ada dan (3) Untuk mengetahui jumlah limbah yang tersedia yaitu dengan menghitung rendemen industri pengolahan kayu.

Berdasarkan informasi yang diperoleh penggergajian kayu dapat menghasilkan limbah yang berupa serbuk kayu sebesar $10 \%$, serutan $25 \%$ dan potongan $14 \%$ sedangkan rendemen pelet kayu adalah $80 \%$ dari serbuk gergajian. Industri Perkayuan merupakan suatu sistem, sehingga perlu diketahui bagaimana bentuk struktur sistemnya. Untuk memahami fenomena usaha Industri Perkayuan diperlukan suatu kerangka pendekatan yang sederhana. 
Hubungan sub sistem dalam sistem usaha industri kayu terkait secara simultan dan dinamis. Perubahan pada salah satu sub sistem akan mempengaruhi sub sistem yang lain, baik secara internal maupun perubahan eksternal. Secara garis besar penjabaran ke dua sub sistem tersebut adalah:

a. Sub sistem produksi yaitu potensi industri pengolahan kayu dan pengembangan teknologi

b. Sub sistem pengolahan yaitu kebutuhan bahan baku, tenaga kerja yang mempunyai keahlian

c. Sub sistem pemasaran antara lain sistem pemasaran dan persaingan harga

d. Sub sistem kelembagaan meliputi, lembaga sosial dan ekonomi

\section{Alat dan Bahan}

Alat penelitian yang digunakan mesin. Berbahan baku serbuk kayu dan tepung tapioka sebagai perekat. Serbuk kayu yang sudah diolah berupa serat.

\section{Prosedur Penelitian}

Dalam prosedur pembuatan pelet serbuk kayu dengan teknik densifikasi ada beberapa tahapan proses yang dilalui meliputi persiapan bahan baku, pencampuran perekat, penempaan, pengeringan dan analisa hasil.

\section{HASIL DAN PEMBAHASAN}

Berdasarkan hasil survey produksi ada beberapa tahapan yang dilakukan terkait proses pembuatan Biopellet berikut:

1. Proses pencacahan, meliputi penyaringan serbuk kayu, di mana serbuk kayu atau bahan baku mentah yang masih kasar potong-potong cacah dengan mesin hingga menjadi serpihan yang lebih kecil.

2. Proses pengeringan, serbuk kayu yang sudah di cacah (di haluskan) di hisap ke dalam tungku pengeringan agar kadar air dalam serbuk kayu tidak terlalu banyak, di tampung dalam tabung syclon hingga keluar berbentuk chips.

3. Bahan baku yang masih berbentuk chips, di proses melalui mesin penghisap untuk seleksi penyerbukan. Masuk kemudian ke hammar mill untuk proses penyerbukan dan penepungan.

4. Kemudian turun ke pencetak pelet untuk proses pemeletan. Keluar dalam bentuk pelet pada bagian confliyer.

5. Proses packing atau tahap akhir penimbangan dan pembungkusan. Pelet yang sudah jadi di timbang dalam satuan kilogram $(\mathrm{kg}$ ) berukuran 60-75 ml, berdiameter $6 \mathrm{~mm}$ di bungkus dalam kemasan karung hingga berat $20-25 \mathrm{~kg}$.

Dalam proses produksinya, pelet kayu sangat bergantung pada pengaturan kadar air dan kualitas lignin jenis kayu yang dijadikan pelet. Mesin produksi memiliki kapasitas $300 \mathrm{~kg}$ per jam, dengan daya listrik $150 \mathrm{kWh}$, temperatur 60 derajat celcius. 
Jenis pelet dengan nilai kalor dan kadar air sebagai berikut:

\begin{tabular}{lcc}
\hline \multicolumn{1}{c}{ JENIS } & KALORI (Kcal/kg) & KADAR AIR (\%) \\
\hline Kaliandra & 4417 & 8,8 \\
Gamal & 4197 & 8,3 \\
Raimba Campuran & 4226 & 14,0 \\
\hline
\end{tabular}

Biomass pelet ini dapat diaplikasikan untuk keperluan rumah tangga, industri kecil hingga besar. Jenis pelet dengan harga di pabrik pelet KPH Rinjani Barat:

\begin{tabular}{lcc}
\hline \multicolumn{1}{c}{ JENIS } & CURAH (Rp/Kg) & KEMASAN (Rp/Kg) \\
\hline Kaliandra & 4000 & 5000 \\
Gamal & 3000 & 4000 \\
Rimba Campuran & 2000 & 3000 \\
\hline
\end{tabular}

\section{KESIMPULAN DAN SARAN}

\section{Kesimpulan}

1. Limbah serbuk kayu dapat dimanfaatkan menjadi Biopelet bahan bakar alternatif. Dalam prosedur pembuatan pelet serbuk kayu meliputi beberapa tahapan proses yaitu persiapan bahan baku, pencampuran perekat, penempaan, pengeringan dan analisa hasil.

2. Antusiasme masyarakat terkait pemanfaatan limbah sangat baik. Namun keterbatasan teknologi yang ada di desa Ranjok.

\section{Saran}

Dalam pemanfatan limbah diharapkan pemerintah ikut serta dalam mensosialisasikan terhahadap penanggulangan limbah. Karena tidak menutup kemungkinan pihak terkait.

\section{Ucapan Terima Kasih}

Pertama-tama kami ucapkan segala puji bagi Allah, Tuhan semesta alam yang telah memberikan kami berkah serta rahmatnya hingga kami dapat menyelesaikan artikel penelitian ini.

Yang kedua tak lupa kami haturkan shalawat dan salam kami atas junjungan Nabi besar kita Muhammad SAW, yang telah membawa kita dari alam yang gelap gulita menuju alam yang terang benderang yang adainul islam.

Kami ucapkan terima kasih yang sebesar-besarnya kepada masyarakat desa Ranjok yang telah memberikan kami kesempatan serta dukungan dalam rangka melakukan penelitian program kerja KKN kami.

Terima kasih kepada Bapak Muhammad Ali, S.pt, M.Si., ph.D selaku Dosen Pembimbing Lapangan kami.

\section{DAFTAR PUSTAKA}

KPH Rinjani Barat Pelangan Tastura. Fikri, Moh. Haykal dkk. 2019, Pemanfaatan Serbuk Kayu di desa Ranjok Kecamatan Gunung Sari Kabupaten Lombok Barat sebagai 
Biopelet sebagai Sumber Energi Terbarukan.KKN Tematik 2019, Universitas Mataram, Mataram.

Permata, Dea.2019, Pembuatan Bahan Biopelet dari Limbah Serbuk Gergajian, Skripsi. Fakultas Pertanian, Univ. Lampung, Bandar Lampung.

Bassam EL danMaegaard. Uji Kinerja Rotary Dryer BerdasarkanEfisiensi Termal Pengeringan Serbuk Kayu untuk Pembuatan Biopelet. Jurnal Teknik Kimia No. 21(2), April2015.

Bismarck, A., Mishra, S., Lampke, T. 2005. Plant Fibers as Reinforcement for Green Composites. In: Mohanty, A.K., Misra, M., and Drzal, L.T. (Ed.), Natural Fibers, Biopolymer, and Biocomposites. CRC Press Tailor and Francis group, Boca Raton.

Bhattacharya dan Yamada. 1996. Biomassa Dengan Densitas Rendah. Penerbit Erlangga, Jakarta.

Darmawan 2000 Kandungan Kadar Abu Terhadap Serbuk Gergajian Pada Biomassa (Skripsi) Universitas Muhammadiyah Surakarta. Surakarta. 